\title{
Assessment Of Mania With Self Rating Scale.
}

\author{
Shakya R', Khandelwal SK², Sagar R²
}

1.Associate Professor, Department of Psychiatry, Patan Academy Of Health Sciences, Lalitpur, Nepal 2. Professor, Department of Psychiatry, All India Institute Of Medical Sciences, New Delhi, India.

E-mail *Corresponding author: rabishakya@pahs.edu.np

\begin{abstract}
Introduction: Patients with mania are generally considered unreliable informants about their illness and most of the mania rating scales are clinician administered. There are few self-rating scales in mania and the utility of which is immense.

Objective: The study was aimed to compare the co-relation between the self-rating scales and clinician rating scales in mania.

Method: Forty-two patients with mania in the tertiary care center of North Indian setting were applied with Clinician Administered Rating Scale for Mania,Altman Self-Rating Mania scale, Hamilton Rating Scale for Depression and Clinical Global Impression Scale at base line and consecutive four weeks. The scores were analyzed for correlation.

Result: The Pearson's correlation coefficient rho between self rated vs. clinician in the first week scores was 0.368 with $p$ value of $<0.05$. On the subsequent weeks the rho value progressively increased and became highly significant $(p<0.01)$.

Conclusion: Self- reporting by mania is reliable in looking at the symptoms. Self rating scale is not very reliable when the patient is very severely ill, at least to predict the severity /improvement, but, reliable when the patient improves from very severe illness to moderate or milder degree. The scale can be utilized as an augmentation to the clinical interview.
\end{abstract}

\section{Keywords: Mania, Self Rating, Clinician Rating}

\section{INTRODUCTION}

Unlike the other branches of medicine, in psychiatry a clinician must depend upon the mere clinical interviews and observation for making a diagnosis and monitoring of symptoms. ${ }^{1} \quad$ A variety of structured questionnaires, interviews, check lists, outcome assessments are available to inform psychiatric practice, research, and administration. These instruments, called psychiatric rating scales, are often helpful in standardization of the diagnosis and uniform quantification of symptoms profiles during monitoring patients over time. They provide information that is more comprehensive than that generally obtained in a routine clinical interview. ${ }^{2}$ While several rating scales are available to quantify the severity of depression and anxiety, there is a less satisfactory choice of instruments for mania are limited, more so in case of self- rating. ${ }^{345}$ Although mania rating scales have improved over the years, the few available contain 
deficiencies that may limit their clinical and diagnostic utility. Most of the mania rating scales are observer rated and only a few are selfrated. Generally, it is assumed that manic patients areunreliable informants due to lack of judgment and insight. Hence, to test whether the self rating scales can be compared to the clinician rating scale, this study was planned. The aim of this study is to assess the correlation between the self- rated and observer rated scales of mania.

\section{MATERIAL AND METHOD}

This is an analytical study of 42 consecutive patients with mania in a naturalistic ward setting of AIIMS, New Delhi, a tertiary care center of North India conducted between the period of 2001-2002.Forty-two consecutive patients of age 15-55 years andeither sexes, with the diagnosis of mania according to ICD-10 (Diagnostic Criteria for Research), and those who were co-operative for the assessment with the scales were included. Patients with Organic mental disorder, uncooperative and differently abled for the assessment were excluded.Informed consent were taken from concerned guardian or family member.All the patients were rated with 1) Semi- structured Proforma 2)Clinician Administered Rating Scale for Mania (CARS-M) ${ }^{6} 3$ )Altman Self-Rating Mania scale $\left.(\mathrm{ARSM})^{7}, 4\right)$ Hamilton Rating Scale for Depression (HAM-D) ${ }^{8}$ and 5 ) Clinical Global Impression Scale (CGI) ${ }^{9}$ both severity (S) and Improvement (I) .After the baseline assessment within 48 hrs of admission, each included patient was assessedevery week for next four weeks by the same scales as mentioned above. The data from all the instrument was entered and analyzed using SPSS-10 to look for the Corelation between the two ratings by Pearson's correlation and comparison of serial scores of the same scales by General Linear Regression model (post-hoc analysis). The ethical clearance was obtained from the ethical board of the institution.

\section{RESULT}

All the consecutive patients admitted in the psychiatry ward of AIIMS, and fulfilling the exclusion and inclusion criteria were taken up in order to avoid the selection bias. Out of the 50 included cases 8 had to be dropped out as they met the exclusion criteria. The majority $(76 \%)$ of the patients were male compared to female $(24 \%)$. The mean age of the patient was 29 years (SD 9.8 years). The average number of episode at the time of contact was $3^{\text {rd }}$ (SD 2.3) and the average time lapse between the onset of the illness and hospitalization was 37 days. (SD 180 days). Similarly, the average stay in the hospital was 41 days (SD 34 days).

Table 1 shows the mean score and standard deviations for the scales CARS-M, ASRM, HAM-D, CGIS-S, CGIS-I respectively the initial assessments and the subsequent ratings of the first week through the $4^{\text {th }}$ week:

Table no. 1: Mean score and Standard deviation from the scales (baseline to week 4)

\begin{tabular}{|l|l|l|l|l|l|}
\hline Scales & $\begin{array}{l}\text { Base } \\
\text { line } \\
\text { Mean } \\
\text { (SD) }\end{array}$ & $\begin{array}{l}\text { 1st } \\
\text { week } \\
\text { Mean } \\
\text { (SD) }\end{array}$ & $\begin{array}{l}\mathbf{2}^{\text {nd }} \\
\text { week } \\
\text { Mean } \\
\text { (SD) }\end{array}$ & $\begin{array}{l}\text { 3 }^{\text {wd }} \\
\text { week } \\
\text { Mean } \\
\text { (SD) }\end{array}$ & $\begin{array}{l}\mathbf{4}^{\text {th }} \\
\text { week } \\
\text { Mean } \\
\text { (SD) }\end{array}$ \\
\hline CARS- & 40.3 & 28 & 18.6 & 11.7 & 7.2 \\
M & $(7.83)$ & $(8.75)$ & $(9.52)$ & $(10.27)$ & $(8.77)$ \\
\hline ASRM & 15.69 & 11.02 & 7.57 & 5.78 & 2.85 \\
& $(3.50)$ & $(4.59)$ & $(5.03)$ & $(5.55)$ & $(3.73)$ \\
\hline HAM-D & 5.21 & 2.47 & 2.00 & 1.85 & 1.64 \\
& $(3.26)$ & $(1.61)$ & $(1.68)$ & $(1.66)$ & $(1.49)$ \\
\hline CGIS-S & 5.42 & 4.26 & 3.35 & 2.50 & 1.92 \\
& $(0.70)$ & $(0.98)$ & $(1.02)$ & $(1.19)$ & $(1.19)$ \\
\hline CGIS-I & - & 3.09 & 2.69 & 2.21 & 1.73 \\
& & $(0.79)$ & $(0.92)$ & $(1.20)$ & $(1.17)$ \\
\hline
\end{tabular}

The reliability- analysis scale (alpha) among the respective ASRM and CARSM scores shows the value alpha $=0.8846$. The linear regression model (post hoc analysis) of each reading of respective scales from initial assessments to the serial weekly assessments, show significantly decreasing trends, except for the HAM-D scores.The correlations between the ASRM Vs CARS-M scores (Table 2) shows the Pearson correlation coefficient $(\rho=0.368)$ on the initial assessment which is statistically significant at the $p$ value $<0.05$ on the two tailed analysis. He subsequent assessments i.e. the first through the fourth week show the subsequent increment in the $\rho$ value with $\mathrm{p}$ significance $<0.01$. There is similar correlation between the scores of CGIS-S vs ASRM scores. Table 3. However, the correlation between the scores of CGIS-I vs. ASRM in the first week does not seem to 
correlate significantly, but the subsequent scores from the $2^{\text {nd }}$ through the $4^{\text {th }}$ week do correlate significantly.(Table 4 ).

Table no. 2: Correlations - ASRM vs CARSM

\begin{tabular}{|l|l|l|l|l|l|l|l|l|l|l|}
\hline & \multicolumn{2}{l}{ CARS-M0 } & \multicolumn{2}{l|}{ CARS-M1 } & \multicolumn{2}{l|}{ CARS-M2 } & \multicolumn{2}{l|}{ CARS-M3 } & \multicolumn{2}{l|}{ CARS-M4 } \\
\cline { 2 - 11 } & Rho & $\mathrm{p}$ & Rho & $\mathrm{p}$ & Rho & $\mathrm{p}$ & Rho & $\mathrm{p}$ & & \\
\hline ARSM 0 & .37 & $.03^{*}$ & & & & & & & & \\
\hline ARSM 1 & & & .44 & $<.001^{*}$ & & & & & & \\
\hline ARSM 2 & & & & & .81 & $<0.01^{*}$ & & & & \\
\hline ASRM 3 & & & & & & & .73 & $<0.01^{*}$ & & \\
\hline ASRM4 & & & & & & & & & .83 & $<0.01^{*}$ \\
\hline
\end{tabular}

0= Baseline, 1=First week, 2= Second week, 3= Third week, 4=Fourth week, ${ }^{*}$ significant p value

trends in the scores indicating improvement in the illness in the due course of treatment, which is a very expected outcome. The reliabilityanalysis scale (alpha) among the respective ASR-M and CARS-M scores shows the value alpha $=0.8846$, indicating that each self rating

Table no. 3: Correlations - ASRM vs CIGI Severity

\begin{tabular}{|l|l|l|l|l|l|l|l|l|}
\hline & \multicolumn{2}{|l|}{ CIGI-S 1 } & \multicolumn{2}{l|}{ CIGI-S 2 } & \multicolumn{2}{l|}{ CIGI-S 3 } & \multicolumn{2}{l|}{ CIGI-S 4 } \\
\cline { 2 - 9 } & Rho & $\mathrm{p}$ & Rho & $\mathrm{p}$ & Rho & $\mathrm{p}$ & Rho & $\mathrm{p}$ \\
& & & & & & & & \\
\hline ARSM 1 & .55 & $<0.01^{*}$ & & & & & & \\
\hline ARSM 2 & & & .34 & $.013^{*}$ & & & & \\
\hline ARSM 3 & & & & & .64 & $<0.01^{*}$ & & \\
\hline ASRM 4 & & & & & & & .74 & $<0.01^{*}$ \\
\hline
\end{tabular}

1=First week, 2= Second week, 3= Third week, 4=Fourth week, * significant $p$

Table no. 4: Correlations - ARSM vs CIGI Improvement

\begin{tabular}{|l|l|l|l|l|l|l|l|l|}
\hline & \multicolumn{2}{|l|}{ CIGI-I 1 } & \multicolumn{2}{l|}{ CIGI-I 2 } & \multicolumn{2}{l|}{ CIGI-I 3 } & \multicolumn{2}{l|}{ CIGI-I 4 } \\
\cline { 2 - 9 } & Rho & $\mathrm{p}$ & Rho & $\mathrm{p}$ & Rho & $\mathrm{p}$ & Rho & $\mathrm{p}$ \\
& & & & & & & & \\
\hline ARSM 1 & .81 & .59 & & & & & & \\
\hline ARSM 2 & & & .51 & $<0.01^{*}$ & & & & \\
\hline ARSM 3 & & & & & .60 & $<0.01^{*}$ & & \\
\hline ASRM 4 & & & & & & & .68 & $<0.01^{*}$ \\
\hline
\end{tabular}

1=First week, 2= Second week, 3= Third week, 4=Fourth week,

* significant $p$ value

\section{DISCUSSION:}

The majority of the patients admitted were male that keeps with the epidemiological studies that predict the life time morbidity risk for mania is more for male. ${ }^{10}$ Though we didn't specifically looked at the age of onset of the illness. The mean age of 27 years in the sample for an average of third episode is indirectly similar to the studies published. ${ }^{11}$ The mean length of stay of 41 days is higher than in the other studies. ${ }^{1213}$ However, for third episode a stay of 41 days is comparable to a stay of 28 days for first episode mania. ${ }^{14}$ When we look at the weekly assessments in the score there is decreasing is significantly reliable enough with the respective objective ratings. The value is similar to the results of the original authors (alpha $=0.766$ ) during the making of the scale. ${ }^{6}$ Assuming the samples ( $\mathrm{n}$ 42) large enough to be considered normally distributed, the Pearson Correlation were applied for comparison between the scale scores. The rho value betweenASRM vs. CARSM on the initial scores was 0.368 which was significant at the $p$ value of $<0.05$ but on the subsequent weeks the rho value progressively increased and became highly significant $(\mathrm{p}<0.01)$. However, the correlation between the scores of CGIS-I vs. ASRM in the first week does not seem to correlate significantly, but on the subsequent weeks the rho value progressively increased and became highly significant $(p<0.01)$. This indicates that the ARSM is not very reliable when the patient improves from very severe illness to moderate or milder degree.The lack of correlation in the first week may be explained in the light of extreme distractibility of the manic patients during acute illness that they have difficulty understanding the exact instruction and they tend to fill the score sheet hastily. Our study keeps in line with the other studies showing that the self rating scales have a modest role in Mania. ${ }^{15}$ Self-assessment of mania appears 
feasible and potentially useful in practice; lack of insight, poor judgment, and distractibility obviously require assessment by a clinician. ${ }^{16}$ Self rating scales can also perform well and can be correlated well with the clinician rating scales. ${ }^{17}$ However, there were few limitations of our study. The investigator was not blind to any information about the patient including the scores of all scales. So the bias o recording of the ratings couldnot be completely ruled out. The patient group was not compared with healthy controls or patients with other psychiatric illnesses. Similarly, the scales used in the study does not have any items for assessing dysphoria or the mixed features.

\section{CONCLUSION:}

Altman Self-Rating Mania scale is not very reliable when the patient is very severely ill, at least to predict the severity improvement but reliable when the patient improves from very severe illness to moderate or milder degree. The scale can be utilized as an augmentation to the clinical interview. This scale can also be utilized as a monitoring instrument by the patient himself, the caregiver and also by the physician to watch their progress or for impending illness. However, this scales needs to be translated and validated in different language to make its utility vast.

\section{REFERENCES:}

1. Kaplan S. Textbook of psychiatry.

2. Maust D, Cristancho $M$, Gray $L$, et al. Psychiatric rating scales. Handb Clin Neurol 2012; 106: 227-237.

3. Bech P, Rafaelsen OJ, Kramp P, et al. The mania rating scale: scale construction and interobserver agreement. Neuropharmacology 1978; 17: 430-431.

4. Young RC, Nysewander RW, Schreiber MT. Mania scale scores, signs, and symptoms in forty inpatients. J Clin Psychiatry 1983; 44: 98-100.

5. Beigel A, Murphy DL, Bunney WE. The ManicState Rating Scale: Scale Construction, Reliability, and Validity. Arch Gen Psychiatry 1971; 25: 256-262.

6. Altman EG, Hedeker DR, Janicak PG, et al. The Clinician-Administered Rating Scale for Mania (CARS-M): development, reliability, and validity. Biol Psychiatry 1994; 36: 124-134.
7. Altman EG, Hedeker D, Peterson JL, et al. The Altman Self-Rating Mania Scale. Biol Psychiatry 1997; 42: 948-955.

8. Hamilton M. A rating scale for depression. J Neurol Neurosurg Psychiatry 1960; 23: 56-62.

9. GUY W. CGI Clinical Global Impressions. ECDEU Assess Man Psychopharmacol 1976; 76338.

10. Fogarty F, Russell J m., Newman $S$ c., et al. Mania. Acta Psychiatr Scand 1994; 89: 16-23.

11. Leboyer M, Henry C, Paillere-Martinot M-L, et al. Age at onset in bipolar affective disorders: a review. Bipolar Disord 2005; 7: 111-118.

12. Sajatovic M, Friedman SH, Sabharwal J, et al. Clinical Characteristics and Length of Hospital Stay among Older Adults with Bipolar Disorder, Schizophrenia or Schizoaffective Disorder, Depression, and Dementia. J Geriatr Psychiatry Neurol 2004; 17: 3-8.

13. Tohen $M$, Hennen J, Zarate $C M$, et al. Two-year syndromal and functional recovery in 219 cases of first-episode major affective disorder with psychotic features. Am J Psychiatry 2000; 157: 220-228.

14. Tohen M, Zarate CA, Hennen J, et al. The McLean-Harvard First-Episode Mania Study: prediction of recovery and first recurrence. Am J Psychiatry 2003; 160: 2099-2107.

15. Altman E, Hedeker D, Peterson JL, et al. A comparative evaluation of three self-rating scales for acute mania. Biol Psychiatry 2001; 50: 468471.

16. Akiskal HS, Hantouche EG, Bourgeois ML, et al. Toward a refined phenomenology of mania: combining clinician-assessment and self-report in the French EPIMAN study. I Affect Disord 2001; 67: 89-96.

17. Shugar $G$, Schertzer $S$, Toner BB, et al. Development, use, and factor analysis of a selfreport inventory for mania. Compr Psychiatry 1992; 33: 325-331. 